DOI:

УДК 621.777 .4

Н.С. Грудкіна ${ }^{1}$, д.т.н., доцент, vm.grudkina@ukr.net

І.С. Алієв ${ }^{1}$, д.т.н., професор, igramaliev@gmail.com

Х.В. Малій ${ }^{1}$, к.т.н., старший викладач, kristina.v.goncharuk@gmail.com

В.М. Левченко ${ }^{2}$, к.т.н., старший науковий співробітник, goldangel271@gmail.com

${ }^{1}$ Донбаська державна машинобудівна академія, м. Краматорськ

${ }^{2}$ Інститут радіофізики та електроніки імені О.Я. Усикова НАН України, м. Харків

\title{
РОЗВИТОК ЕНЕРГЕТИЧНОГО МЕТОДУ БАЛАНСУ ПОТУЖНОСТЕЙ НА ОСНОВІ РОЗШИРЕННЯ БАЗИ КІНЕМАТИЧНИХ МОДУЛІВ СКЛАДНОЇ КОНФІГУРАЩЇ̈
}

В даній роботі розвинуто можливості застосування енергетичного методу балансу потужностей для моделювання прочесів холодного видавлювання складнопрофільованих деталей за рахунок розширення бази уніфікованих кінематичних модулів складної конфігурачії. У якості альтернативи прямокутним кінематичним модулям запропоновані кінематичні модулі трапецеїдальної та трикутної форми з виробленням рекомендацій щодо ефективного їх застосування, до дозволило врахувати вплив конструктивних особливостей та поверхонь розділу течї̈ металу всередині заготовки та отримати дані з енергосилових параметрів та формоутворення, щзо відповідають дійсності.

Ключові слова: кінематичний модуль; холодне видавлювання; формоутворення; проектування.

In this paper, the possibilities of applying the energy method of power balance for simulating the processes of cold extrusion of complex parts by expanding the base of unified kinematic modules of complex configuration are developed. As the alternative to rectangular kinematic modules, trapezoidal and triangular ones were proposed with recommendations for their effective use, to take into account the influence of design features and surfaces of the metal flow inside the workpiece and to obtain data on power parameters and shape formation.

Keywords: kinematic module; cold extrusion; shape; design.

\section{Постановка проблеми}

Необхідною умовою успішного впровадження конкурентоспроможних технологій холодного об'ємного штампування видавлюванням $є$ забезпечення визначення оптимальних режимів деформування деталі саме на етапі проектування. При виготовленні складнопрофільованих деталей визначення силових параметрів, оптимальної конфігурації інструменту та ефективних факторів управління формоутворенням, що забезпечують уникнення дефектоутворення, $\epsilon$ актуальними задачами [1-5]. Активному впровадженню на виробництві нових способів видавлювання складнопрофільованих деталей сприятиме розвиток енергетичних методів як ефективних теоретичних методів побудови та аналізу відповідних математичних моделей, що на етапі проектування виявить обмеження та вплив конструктивних і технологічних параметрів на основні якісні показники готових виробів [6-8].

Аналіз останніх досліджень та публікацій

Ефективність застосування енергетичного методу балансу потужностей (ЕМБП) для прогнозування силового режиму, формоутворення та дефектоутворення деталі в процесах холодного вдавлювання продемонстрована в роботах $[6,8-10]$. При моделюванні процесів комбінованого послідовного та суміщеного видавлювання з суцільних та 3 трубчастих заготовок використовували зазвичай комплекс уніфікованих кінематичних модулів найпростішої прямокутної та трапецеїдальної форми з прямолінійною похилою межею. Однак математичні моделі, побудовані на основі спрощених схем паралельної течії із використанням кінематичних модулів прямокутного перерізу, з одного боку не викликають труднощів в обчисленнях, а з іншого можуть призводити до значного розходження 3 експериментальними даними щодо силових параметрів та приростів розмірів напівфабрикату $[7,10]$. 
Таким чином, потреби в урахуванні конфігурації інструменту та особливостей кінематики течії металу, форми осередків інтенсивної деформації вимагають розробки нових кінематичних модулів складної конфігурації. Розвитку можливостей енергетичного методу балансу потужностей на основі розширення бази кінематичних модулів трапецеїдальної та трикутної форми присвячено ряд робот [11-15]. Виявлено проблеми значного ускладнення математичного апарату та необхідність використання прийомів спрощення виразів приведеного тиску деформування, що дозволяють отримати відповідні інженерні формули для розрахунків силового режиму процесів холодного видавлювання трикутної або трапецеїдальної форми 3 похилими межами [13-15]. Однак основні результати досліджень стосуються побудови розрахункової схеми цілком визначеного процесу, а більш системного аналізу щодо вироблення рекомендацій із раціональності використання кінематичних модулів складної конфігурації як альтернативи кінематичним модулям прямокутної форми проведено не було.

\section{Формулювання мети дослідження}

Метою роботи є розвинення енергетичного методу балансу потужностей для моделювання процесів холодного видавлювання складнопрофільованих деталей за рахунок розширення бази кінематичних модулів складної конфігурації, вироблення рекомендацій щодо ефективного їх застосування для ефективного прогнозування енергосилових параметрів та формоутворення деталей.

\section{Виклад основного матеріалу}

Можливості оперативного використання різних типів кінематичних модулів в базовій розрахунковій схеми дозволяють врахувати вплив конфігурації інструменту (введення заокруглень або фасок, конусності пуансону та ін.) на формоутворення та дефектоутворення деталей, що $є$ особливо важливим для моделювання процесів комбінованого видавлювання з декількома ступенями свободи течії. При цьому використання тільки прямокутних кінематичних модулів для процесів з одним ступенем свободи течії не дозволяє провести оптимізацію приведеного тиску деформування за геометричними параметрами, і таким чином, позбавляє основних переваг даного теоретичного методу та призводить до завищених у порівнянні з експериментальними даними оцінок енергосилових параметрів. Розробка нових кінематичних модулів трикутної та трапецеїдальної форми дозволить більш чітко описувати поверхні розділу течії всередині заготовки та поверхні контакту заготовки і інструменту. Це сприятиме розширенню можливостей використання відомих кінематичних модулів, окреслить напрямки пошуку нових кінематичних модулів та їх комплексів, і таким чином, підвищить можливості енергетичного методу балансу потужностей як ефективного методу моделювання процесів видавлювання складнопрофільованих деталей.

Основними ознаками кінематичних модулів зазвичай вважають їх форму і розташування, наявність похилих меж та їх варіативність або обмеження та кількість ступенів свободи течії $[9,11,14]$. Однак для забезпечення оперативності вбудовування в нові розрахункові схеми видавлювання складнопрофільованих деталей необхідно вирішити питання відображення складної конфігурації інструменту (заокруглень, форми фасок, торцю пуансону, тощо) або форми поверхні розділу течії металу всередині заготовки, що особливо важливе при зміні течії металу від поздовжнього до поперечного напрямку або навпаки (рис. 1). Згідно проведеного аналізу виявлена необхідність у вдосконаленні відомих кінематичних модулів трапецеїдальної та трикутної форми за рахунок варіювання похилої межі та заміни прямокутних кінематичних модулів комплексом двох чи більше модулів більш складної форми із вирішенням питання доцільності такої заміни. Продемонструвати приклади необхідності розробки нових кінематичних модулів із заокругленням, що визначається конфігурацією поверхонь контакту матриць із заготовкою, можна на прикладі процесу комбінованого послідовного видавлювання з суцільної заготовки (рис. 1, а). При цьому отримані раніше розрахунки ЕМБП використовували побудову спрощеної моделі (без урахування заокруглення), що призводило до завищених оцінок тиску деформування. $[7,13]$. Також враховуючи дані про розподіл інтенсивності напружень для матеріалу АД 31 в процесі послідовного радіально-прямого видавлювання (рис. 1, б) постало питання про виявлення умов доцільності заміни найуживанішого осьового прямокутного модуля 2 на комплекс модулів $2^{*}$ (рис. 1 , а) з розробкою відповідних рекомендацій. 


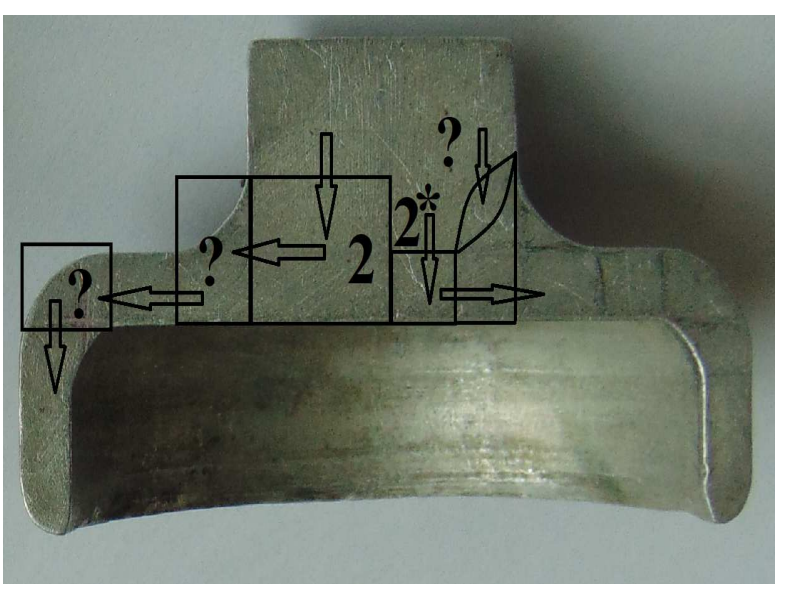

a

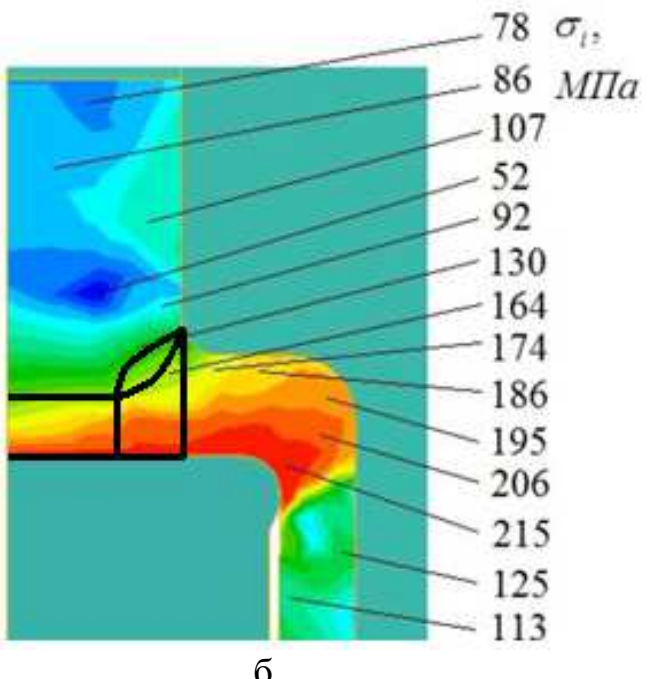

6

Рис. 1. Деталь і приклади розбиття на модулі (а) та розподіл інтенсивності напружень (б) в процесі послідовного радіально-прямого видавлювання для АД31

Можливості оперативності ЕМБП значно збільшуються за умови вироблення чітких рекомендацій використання комплексу альтернативних кінематичних модулів в залежності від форми осередку деформації та набору суміжних кінематичних модулів. Для схеми комбінованого послідовного радіально-прямого видавлювання (рис. 2, а) можливі варіації розрахункових схем та їх складових враховують як зміни в конфігурації інструменту (рис. 2, в), так і наявність різних форм осередку деформації в осьовій зоні $2^{*}$ розвороту металу до радіальної течії (рис. 2, б).

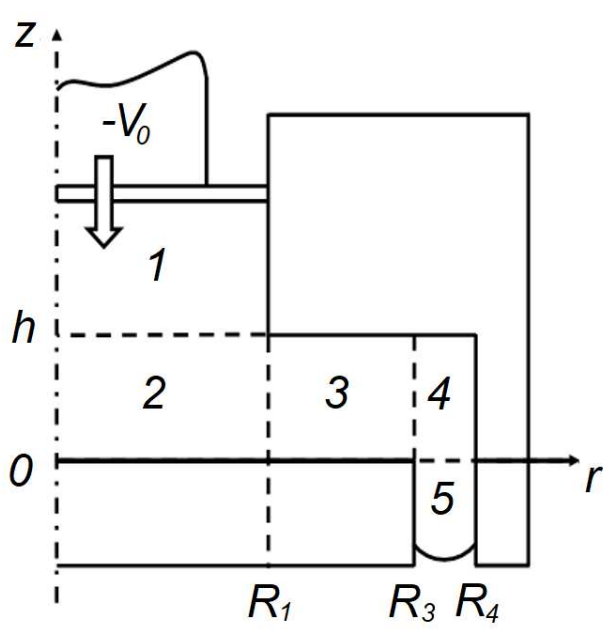

a

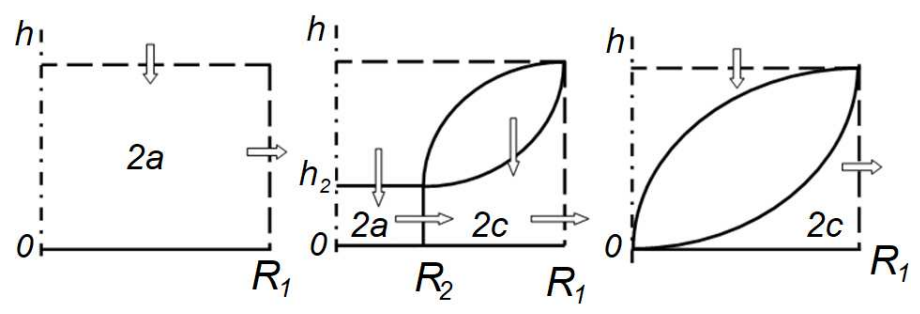

б
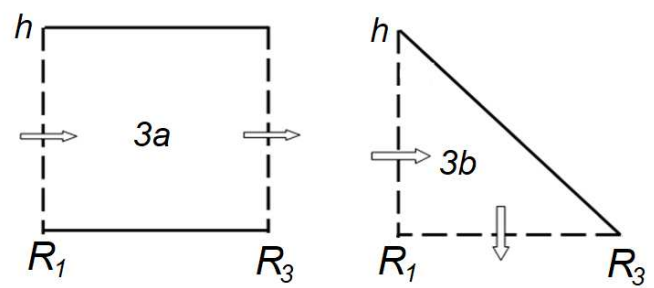

B

Рис. 2. Узагальнена розрахункова схема (а) та варіації модулів осьової зони (б) та зовнішніх кінематичних модулів (в) процесу послідовного радіально-прямого видавлювання

В роботі [15] було запропоновано використовувати у вигляді альтернативного комплексу $2^{*}$ два різних комплекси 2а-2в та 2a-2c, що складаються із осьового прямокутного $2 \mathrm{a}$ та кільцевого трапецеїдального модуля 2в (без вертикальної складової швидкості деформації) та модуля 2c iз наявністю вертикальної складової. Доведено, що раціональним однозначно $є$ комплекс 2a-2c, що забезпечується можливістю оптимізації. Наведемо кінематично можливі поля швидкостей (КМПШ) комплексу модулів 2a-2c: 


$$
\left\{\begin{array} { l } 
{ V _ { z 2 a } = - \frac { V _ { 0 } } { h _ { 2 } } z , } \\
{ V _ { z 2 a } = \frac { V _ { 0 } } { 2 h _ { 2 } } r , }
\end{array} \quad \left\{\begin{array}{l}
V_{z 2 c}=-\frac{\alpha V_{0}}{h} z, \\
V_{z 2 c}=\frac{V_{0}\left[R_{1}^{2}(1-\alpha)+\alpha r^{2}\right]}{2 h r},
\end{array}\right.\right.
$$

де $h_{2}=\frac{R_{2}^{2} h}{R_{1}^{2}(1-\alpha)+\alpha R_{2}^{2}}, z(r)=\frac{h r^{2}}{R_{1}^{2}(1-\alpha)+\alpha r^{2}}$.

При цьому можна розглядати граничні випадки комплексу 2a-2c у вигляді найпростішого прямокутного модуля ( $R_{2}=R_{0}$, трапецеїдальний кільцевий модуль 2 с вироджується) та криволінійного трикутного кінематичного модуля $2 \mathrm{c}\left(R_{2}=0\right.$, прямокутний осьовий модуль $2 \mathrm{a}$ вироджується).

Форма кривої, що визначає похилу межу трапецеїдального кільцевого модуля 2c, залежить від параметру б, який може виступати у якості параметра оптимізації в подальших розрахунках приведеного тиску деформування. Вплив на характеристики кривої $z(r)$ цього параметра $\alpha \in(0,1)$ представлений нижче (рис. 3), при цьому надалі будемо використовувати відносні геометричні параметри процесу $\bar{R}_{1}=1, \bar{h}=h / R_{1}, \bar{R}_{2}=R_{2} / R_{1}$ та $\bar{R}_{3}=R_{3} / R_{1}$.

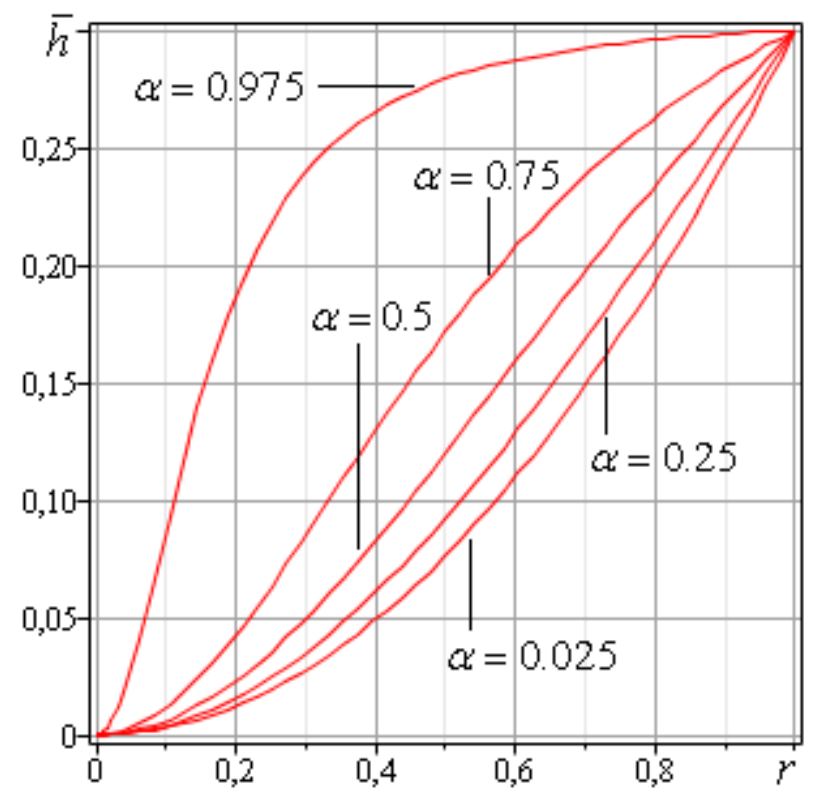

Рuc. 3. Форми похилої межі кінематичного модуля $2 c$

Використовуючи відносні геометричні параметри процесу $\bar{R}_{1}=1$ та $\bar{h}=h / R_{1}$, отримаємо величину приведеного тиску деформування для комплексу 1-2 із урахуванням величини потужності сил деформування, тертя та повної величини зрізу між модулями 1-2 та без урахування складової 2-3, що залежить від варіації суміжного кінематичного модуля 3 :

$$
\bar{p}_{2 a}=1+\left(1+2 \mu_{s}\right) \frac{1}{3 \sqrt{3} \bar{h}} .
$$

Розрахунки складових приведеного тиску деформування комплексу кінематичних модулів $2 a \_2 c$ отримано без урахування потужності сил зрізу модулів 2-3 з огляду на наявність їх варіативності [15]: 


$$
N_{d 2 a_{-} 2 c}=\frac{2 A_{1} \pi \sigma_{S} V_{0}}{\alpha \sqrt{3}}\left[\begin{array}{l}
\frac{\alpha \sqrt{3}}{2 A_{1}} R_{2}^{2}+\frac{\sqrt{3}}{1-A_{2}^{2}}-\frac{\sqrt{3}}{1-A_{3}^{2}}+ \\
+\frac{3}{2} \ln \left|\frac{\left(1-A_{2}\right)\left(1+A_{3}\right)}{\left(1+A_{2}\right)\left(1-A_{3}\right)}\right|+\sqrt{3} \ln \left|\frac{\left(\sqrt{3} A_{2}+1\right)\left(A_{3}-\sqrt{3}\right)}{\left(A_{2}-\sqrt{3)\left(\sqrt{3} A_{3}+1\right)}\right.}\right|
\end{array}\right],
$$

де $A_{1}=\frac{(1-\alpha) R_{1}^{2}}{\sqrt{3}}, A_{2}=\frac{\sqrt{(1-\alpha)^{2}+3 \alpha^{2}}+\alpha-1}{\alpha \sqrt{3}}, A_{3}=\frac{\sqrt{(1-\alpha)^{2} R_{1}^{2}+3 \alpha^{2} R_{2}^{2}}+\alpha-1}{\alpha \sqrt{3} R_{2}^{2}}$;

$$
N_{c 2 a \_2 c}=\frac{\pi \sigma_{S} R_{2} h_{2} V_{0}}{\sqrt{3}}\left(1-\alpha \frac{h_{2}}{h}\right)
$$

$$
N_{t 2 a_{-} 2 c_{-} 0}=\frac{2 \pi \sigma_{S} \mu_{S} V_{0}}{\sqrt{3} h}\left(\frac{R_{2}^{3} h}{3 h_{2}}+R_{1}^{2}(1-\alpha)\left(R_{1}-R_{2}\right)+\alpha \frac{R_{1}^{3}-R_{2}^{3}}{3}\right) \text {; }
$$

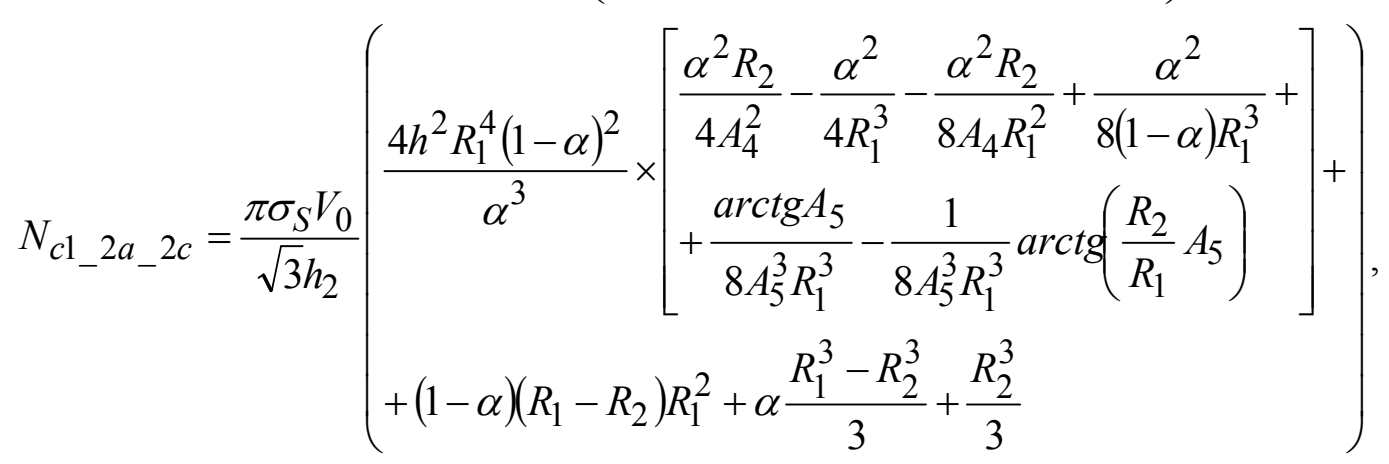

де $A_{4}=(1-\alpha) R_{1}^{2}+\alpha R_{2}^{2} ; A_{5}=\sqrt{\frac{\alpha}{1-\alpha}}$.

Із урахуванням (3)-(7), отримаємо базову величину приведеного тиску деформування для комплексу $2 a-2 \mathrm{c}$ :

$$
\bar{p}_{2 a \_2 c}\left(R_{2}, \alpha\right)=\frac{\sum N d+\sum N_{c}+\sum N_{t}}{\pi \sigma_{S} V_{0} R_{1}^{2}} .
$$

При чому, враховуючи можливість використання вище наведених складових (3-7) для отримання приведеного тиску деформування кінематичного модуля $2 c$ як частинного випадку комплексу кінематичних модулів $2 a \_2 c$, маємо:

$$
\bar{p}_{2 c}(\alpha)=\left.\bar{p}_{2 a \_2 c}\left(R_{2}, \alpha\right)\right|_{R_{2}=0} .
$$

Враховуючи значний вплив саме потужності сил зрізу між суміжними кінематичними модулями зон 2 та 3, отримано відповідні вирази для варіації найуживаніших кінематичних модулів зони 3 у вигляді $3 a$ та $3 в$ :

$$
\begin{gathered}
N_{c 2 a_{-} 3 a}=\frac{\pi \sigma_{S} R_{1} h V_{0}}{\sqrt{3}} ; \\
N_{c 2 a_{-} 3 b}=\frac{\pi \sigma_{S} R_{1} h}{\sqrt{3}} V_{0}\left|\frac{R_{1}\left(3 R_{1}+R_{3}\right)}{2\left(R_{3}^{2}-R_{1}^{2}\right)}-1\right| ; \\
N_{c 2 a_{-} 2 c_{-} 3 a}=N_{c 2 c \_3 a}=\frac{\pi \sigma_{S} \alpha R_{1} h V_{0}}{\sqrt{3}} ; \\
N_{c 2 a_{-} 2 c_{-} 3 b}=N_{c 2 c_{-} 3 b}=\frac{\pi \sigma_{S} R_{1} h}{\sqrt{3}} V_{0}\left|\frac{R_{1}\left(3 R_{1}+R_{3}\right)}{2\left(R_{3}^{2}-R_{1}^{2}\right)}-\alpha\right| .
\end{gathered}
$$


Враховуючи варіативність зовнішніх кінематичних модулів зони 3 та попередньо отримані вирази (1), (6) та (7), величина приведеного тиску деформування приймає вигляд:

$$
\bar{p}_{2 i_{-} 3 j}=\bar{p}_{2 i}+\frac{N_{c 2 i_{-} 3 j}}{\pi \sigma_{S} V_{0} R_{1}^{2}} ;
$$

де $i$ відповідає варіаціям зони 2 у вигляді $2 a, 2 a \_2 c$ та частинного випадку $2 c, j$ відповідає кінематичним модулям зони 3 у вигляді $3 a$ та $3 b$.

Вибір варіативності кінематичних модулів $3 a$ та $3 b$ обумовлений як забезпеченням врахування конфігурації інструменту, так і досить великою відмінністю у побудові КМПШ, а саме відсутністю вертикальної складової швидкості деформації для модуля $3 a$ та зміною напрямку з радіального на пряме видавлювання в межах модуля $3 b$. При чому використання виразів у вигляді (13) дозволить зробити висновки щодо раціональності використання різних модулів, що моделюють течію металу у осьовій зоні 2 , в залежності від різновидів суміжних модулів зони 3 із урахуванням параметрів оптимізації у вигляді $R_{2}$ та $\alpha$ для комплексу $2 a \_2 c$, тільки $\alpha$ для його частинного випадку $2 c$ і неможливості такої оптимізації для найпростішого випадку $2 a$.

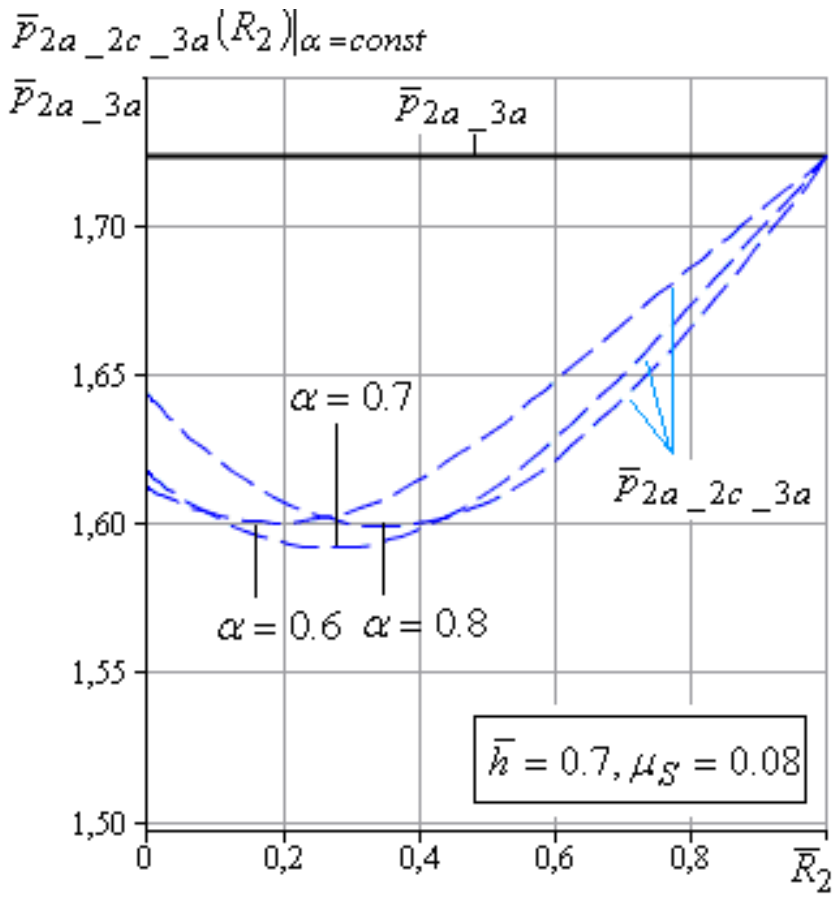

a

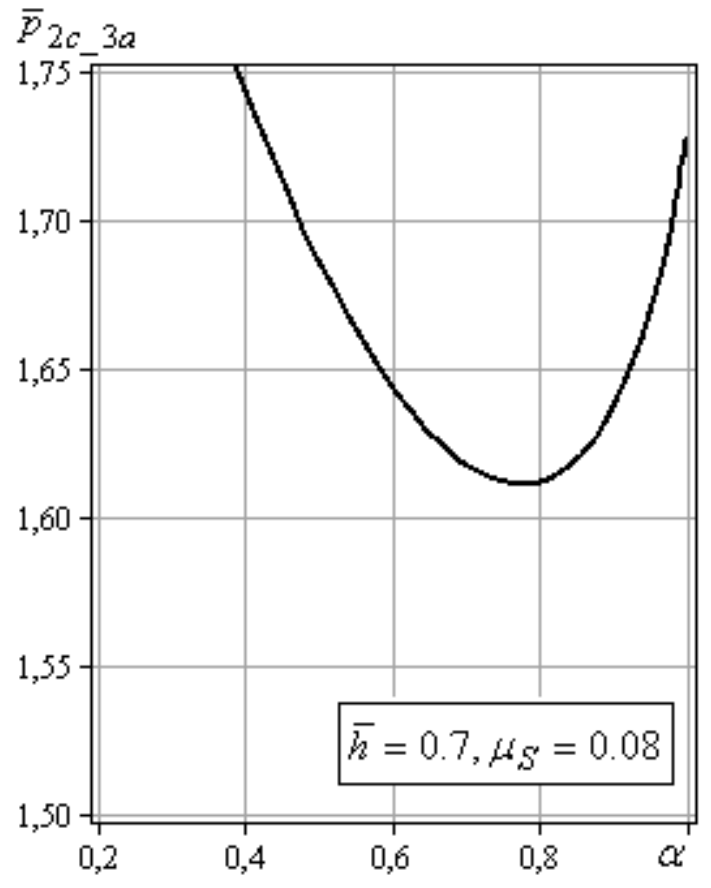

б

Puc. 4. Порівняльний аналіз величин приведених тисків деформування $\bar{p}_{2 a \_3 a} \mathrm{i}$ $\left.\bar{p}_{2 a_{-} 2 c_{-} 2 a}\left(R_{2}\right)\right|_{\alpha=\text { const }}$ (а) та $\bar{p}_{2 c_{-} 2 a}($ ()

Проведемо порівняльний аналіз величин $\bar{p}_{2 a} 3 a$ за формулою (13) із урахуванням (2) та (9) для прямокутних кінематичних модулів (стала величина, рис. 4, а) та величини $\bar{p}_{2 a_{-} 2 c_{-} 3 a}\left(R_{2}, \alpha\right)$ згідно (13) із урахуванням (7) та (11), яку для наочності представимо у вигляді перерізів поверхонь $\bar{p}_{2 a_{-} 2 c_{-} 3 a}\left(R_{2}, \alpha\right)$ кривими $\left.\bar{p}_{2 a_{-} 2 c_{-} 2 a}\left(R_{2}\right)\right|_{\alpha=c o n s t}$ (рис. 4 , а) та частинним випадком у вигляді $\bar{p}_{2 c_{-} 3 a}$ (рис. 4, б). Аналіз поведінки функцій $\left.\bar{p}_{2 a_{-} 2 c_{-} 3 a}\left(R_{2}\right)\right|_{\alpha=\text { const }}$ та $\bar{p}_{2 c_{-} 2 a}$ вказує на наявність точок мінімуму та можливість оптимізації приведених тисків деформування на противагу сталості величини $\bar{p}_{2 a_{-} 3 a}$ для 
найпростішого випадку моделювання форми зони 2 (рис. 4). При цьому комплекс модулів $2 a \_2 c$ (рис. 4 , а) демонструє нижчі оптимальні значення приведеного тиску деформування по відношенню до криволінійного трикутного модуля $2 c$ (рис. 4 , б), відхилення від найпростішого випадку зон 2 і 3 (використання $\bar{p}_{2 a_{-} 3 a}$ ) може складати до 5-10\%. Це пояснюється можливістю оптимізації за двома параметрами $R_{2}$ та $\sigma$ у першому випадку та наявності тільки одного параметру б у другому випадку.

Характер кривих $\left.\bar{p}_{2 a \_2 c \_3 b}\left(R_{2}\right)\right|_{\alpha=c o n s t}$ (рис. 4 , а) та частинним випадком у вигляді $\bar{p}_{2 c_{-} 3 b}$ (рис. 5) є аналогічним до випадку суміжності із кінематичним модулем $3 a$ (рис. 4), однак відхилення приведених тисків деформування, розрахованих для комплексу $2 a \_2 c$ (рис. 5, а) та його частинного випадку у вигляді 2c у поєднанні із зовнішнім кільцевим трикутним кінематичним модулем $3 b$ (рис.5, б) не перевищує $1 . .2 \%$, що можна вважати неістотним. Такі незначні відмінності можна пояснити зниженням впливу повного виразу потужності сил зрізу $N_{c 2 c} c_{3}$ д для межування із зовнішнім трикутним кінематичним модулем із наявністю від’ємної вертикальної складової у його КМПШ. Раціональним у даному випадку можна вважати використання трикутного кінематичного модуля у вигляді $2 c$.
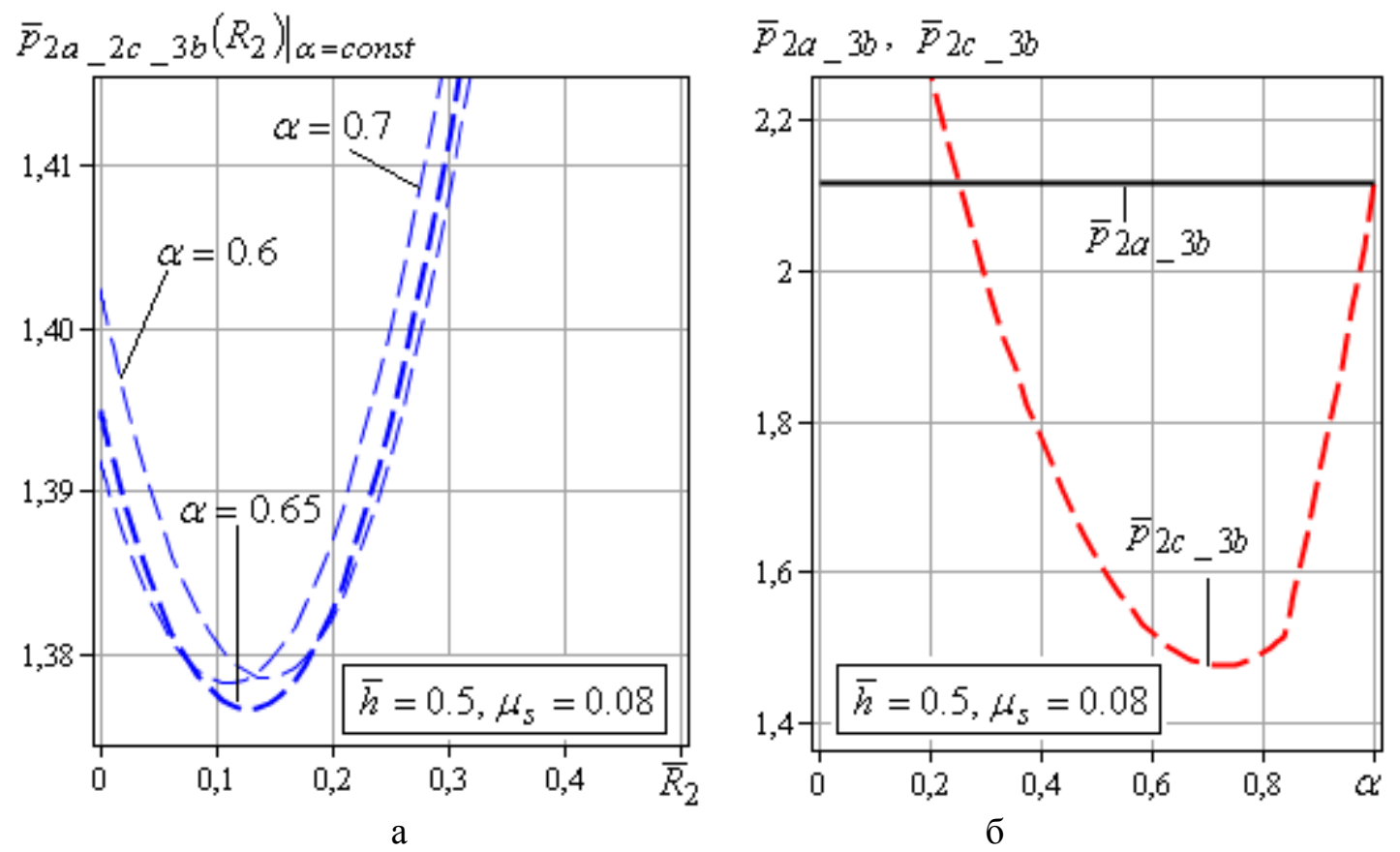

Puc. 5. Порівняльний аналіз величин приведених тисків деформування $\bar{p}_{2 a \_3 a} \mathrm{i}$ $\left.\bar{p}_{2 a \_2 c \_2 a}\left(R_{2}\right)\right|_{\alpha=\text { const }}$ (a) та $\bar{p}_{2 c_{-} 2 a}$

\section{Висновки}

У якості альтернативи найпростішим прямокутним кінематичним модулям запропоновано використання трапецеїдальних кінематичних модулів та їх комплексів. Порівняльний аналіз величин приведеного тиску деформування для базових схем і варіації зовнішніх кільцевих кінематичних модулів виявив нераціональність моделювання осьової зони у вигляді прямокутного кінематичного модуля. При використанні комплексу кінематичних модулів оптимізація приведеного тиску деформування можлива за двома параметрами, що визначають форму та розміри прямокутного та трапецеїдального кінематичних модулів із можливістю виродження у криволінійний трикутний модуль. По відношенню до найпростішого розбиття тільки із наявністю прямокутних кінематичних модулів використання комплексу модулів є раціональним для 
будь-яких варіантів процесу, особливо при наявності розвинутої радіальної течії у суміжних кінематичних модулях (вдається досягти зменшення прогнозованої величини приведеного тиску деформування до 10 \%). Для випадку межування із суміжним кільцевим кінематичним модулем трикутної форми для моделювання осьової зони рекомендовано обирати трикутний кінематичний модуль.

\section{Список використаної літератури}

1. Bhaduri A. Extrusion. Mechanical Properties and Working of Metals and Alloys. Springer Series in Materials Science. 2018. 264. pp. 599-646. https://doi.org/10.1007/978-981-107209-3 13.

2. Aliev I.S. Radial extrusion processes. Soviet Forging and Metal Stamping Technology. In: English Translation of Kuznechno-Shtampovochnoe Proizvodstvo. 1988. Part 3. pp. 54-61. ISSN 0891$334 \mathrm{x}$

3. Jafarzadeh H., Barzegar S., Babaei A. Analysis of Deformation Behavior in Backward-RadialForward Extrusion Process. Trans Indian Inst Met. 2015.68 . pp. 191-199. https://doi.org/10.1007/s12666-014-0441-4

4. Farhoumand A., Ebrahimi R. Experimental investigation and numerical simulation of plastic flow behavior during forward-backward-radial extrusion process. Progress in Natural Science: Materials International. 2016. 26. pp. 650-656.

5. Ogorodnikov V.A., Derevenko I.A., Sivak R.I. On the Influence of Curvature of the Trajectories of Deformation of a Volume of the Material by Pressing on Its Plasticity Under the Conditions of Complex Loading. Materials Science. 2018. 54. 3. pp. 326-332. https://doi.org/10.1007/s11003018-0188-X.

6. Aliieva L., Hrudkina N., Aliiev I., Zhbankov I. and Markov O. Effect of the tool geometry on the force mode of the combined radial-direct extrusion with compression, Eastern-European Journal of Enterprise Technologies, 2020. 2. 1 (104), pp. 15-22. doi:10.15587/1729-4061.2020.198433.

7. Kalyuzhnyi V.L., Aliieva L.I., Kartamyshev D.A., Savchinskii I.G. Simulation of Cold Extrusion of Hollow Parts. Metallurgist. 2017. 61. 5-6, pp. 359-365. https://doi.org/10.1007/s11015-0170501-1.

8. Алиева Л.И. Совершенствование процессов комбинированного выдавливания: монография. Краматорск: ООО «Тираж - 51». 2018. 352 с. ISBN 978-966-379-846-2.

9. Hrudkina N.S., Aliieva L.I. Modeling of cold extrusion processes using kinematic trapezoidal modules. FME Transactions, 2020. 48. 2. pp. 357-363. doi:10.5937/fme2002357H.

10. Hrudkina N., Aliieva L., Markov O., Marchenko I., Shapoval A., Abhari P., Kordenko M. Predicting the shape formation of hollow parts with a flange in the process of combined radialreverse extrusion. Eastern-European Journal of Enterprise Technologies, 2020. 106. 4/1. pp. 5562. https://doi.org/10.15587/1729-4061.2020.203988.

11. Степанский Л.Г. Расчеты процессов обработки металлов давлением. Москва : Машиностроение. 1979. 215 с.

12. Чудаков П.Д. Верхняя оценка мощности пластической деформации с использованием минимизирующей функции. Известия вузов. Машиностроение. 1992. № 9. С. 13-15.

13. Hrudkina N., Aliieva L. Markov O., Kartamyshev D., Shevtsov S., Kuznetsov M. Modeling the process of radial-direct extrusion with expansion using a triangular kinematic module. EasternEuropean Journal of Enterprise Technologies, 3. 1 (105), pp. 17-22, 2020, doi: 10.15587/17294061.2020.203989.

14. Hrudkina N.S. Process modeling of sequential radial-direct extrusion using curved triangular kinematic module. FME Transactions, 2021. 49. 1, pp. 56-63. 2021. doi:10.5937/fme2101056H

15. Грудкіна Н.С. Математичне моделювання процесів радіально-поздовжнього видавлювання 3 використанням трапецеїдальних кінематичних модулів. Вісник КрНУ імені Михайла Остроградського. 2020. № 4 (123). C. 78-83. DOI: 10.30929/1995-0519.2020.4.78-83 


\title{
DEVELOPMENT OF THE ENERGY METHOD OF POWER BALANCE BASED ON THE EXPANSION OF THE BASE OF KINEMATIC MODULES OF COMPLEX CONFIGURATION \\ Hrudkina N., Aliiev I., Malii K., Levchenko V.
}

\begin{abstract}
The necessary condition for the successful implementation of competitive technologies of cold volume extrusion stamping is to ensure the determination of optimal modes of deformation of the part at the design stage. In the manufacturing of complex parts to determine the force parameters the optimal configuration of the tool, the effective factors of control of the formation and ensuring the avoidance of defects, are urgent tasks.

In this paper, the possibilities of applying the energy method of power balance for simulating the processes of cold extrusion of complex parts by expanding the base of unified kinematic modules of complex configuration are developed.

As the alternative to the simplest rectangular kinematic modules, the use of trapezoidal ones and their complexes is proposed. Comparative analysis of the values of the reduced deformation pressure for the basic schemes and variations of the outer annular kinematic modules revealed the irrationality of the simulating of the axial zone in the form of a rectangular kinematic module. When using set of kinematic modules, the optimization of the reduced deformation pressure is possible by two parameters that determine the shape and size of rectangular and trapezoidal kinematic modules with the possibility of degeneration into curvilinear triangular module. With respect to the simplest scheme with presence only of rectangular kinematic modules, the use of set of modules is rational for any process factors, especially in the presence of developed radial flow in adjacent kinematic modules (it is possible to reduce the predicted value of reduced deformation pressure to $10 \%$ ). For the case of neighborhood with the adjacent annular kinematic module of triangular shape, it is recommended to choose the triangular kinematic module for modeling the axial zone.
\end{abstract}

\section{References}

[1] Bhaduri A. (2018). Extrusion. Mechanical Properties and Working of Metals and Alloys. Springer Series in Materials Science, 264. 599-646. https://doi.org/10.1007/978-981-10-7209-3 13 [In English].

[2] Aliev I.S. (1988). Radial extrusion processes. Soviet Forging and Metal Stamping Technology. English Translation of Kuznechno-Shtampovochnoe Proizvodstvo. Part 3. 54-61 . ISSN 0891334x [In English].

[3] Jafarzadeh H., Barzegar S., Babaei A. (2015). Analysis of Deformation Behavior in BackwardRadial-Forward Extrusion Process. Trans Indian Inst Met., 68. 191-199. https://doi.org/10.1007/s12666-014-0441-4 [In English].

[4] Farhoumand A., Ebrahimi R. (2016). Experimental investigation and numerical simulation of plastic flow behavior during forward-backward-radial extrusion process. Progress in Natural Science: Materials International, 26. 650-656. [In English].

[5] Ogorodnikov V.A., Derevenko I.A., Sivak R.I. (2018). On the Influence of Curvature of the Trajectories of Deformation of a Volume of the Material by Pressing on Its Plasticity Under the Conditions of Complex Loading. Materials Science, 54. 3. 326-332. https://doi.org/10.1007/s11003018-0188-x. [In English].

[6] Aliieva L., Hrudkina N., Aliiev I., Zhbankov I., Markov O. (2020). Effect of the tool geometry on the force mode of the combined radial-direct extrusion with compression, Eastern-European Journal of Enterprise Technologies, 2, 1 (104). 15-22, doi:10.15587/1729-4061.2020.198433. [In English].

[7] Kalyuzhnyi V.L., Aliieva L.I., Kartamyshev D.A., Savchinskii I.G. (2017). Simulation of Cold Extrusion of Hollow Parts. Metallurgist, 61. 5-6. 359-365. https://doi.org/10.1007/s11015-0170501-1. [In English]. 
[8] Aliieva L.I. (2018.) Sovershenstvovanie protsessov kombinirovannogo vyidavlivaniya : monografiya. [Improvement of combined extrusion processes: monograph]. Kramatorsk: LLC «Tirazh51». ISBN 978-966-379-846-2. [In Russian].

[9] Hrudkina N.S., Aliieva L.I. (2020). Modeling of cold extrusion processes using kinematic trapezoidal modules. FME Transactions, 48. 2. 357-363. doi:10.5937/fme2002357H. [In English].

[10] Hrudkina N., Aliieva L., Markov O., Marchenko I., Shapoval A., Abhari P., Kordenko M. (2020). Predicting the shape formation of hollow parts with a flange in the process of combined radial-reverse extrusion. Eastern-European Journal of Enterprise Technologies, 106. 4/1. 55-62. https://doi.org/10.15587/1729-4061.2020.203988. [In English].

[11] Stepanskij L.G. (1979). Raschety processov obrabotki metallov davleniem. [Calculations of metal forming processes]. Moskva: Mashinostroenie. [In Russian].

[12] Chudakov P.D. (1992). Verhnyaya ocenka moshchnosti plasticheskoj deformacii $\mathrm{s}$ ispol'zovaniem minimiziruyushchej funkcii. [Upper bound for the plastic strain rate using a minimizing function]. Izvestiya vuzov. Mashinostroenie. 9. 13-15. [In Russian].

[13] Hrudkina N., Aliieva L. Markov O., Kartamyshev D., Shevtsov S., Kuznetsov M. (2020). Modeling the process of radial-direct extrusion with expansion using a triangular kinematic module, Eastern-European Journal of Enterprise Technologies, 3, 1 (105), 17-22. doi: 10.15587/17294061.2020.203989. [In English].

[14] Hrudkina N.S. (2021). Process modeling of sequential radial-direct extrusion using curved triangular kinematic module. FME Transactions, 49. 1. 56-63. doi:10.5937/fme2101056H [In English].

[15] Grudkina N.S. (2020). Matematichne modelyuvannya procesiv radial'no-pozdovzhn'ogo vidavlyuvannya $\mathrm{z}$ vikoristannyam trapeceïdal'nih kinematichnih moduliv. [Mathematical modeling of radial-lateral extrusion processes using trapezoidal kinematic modules]. Visnik KrNU imeni Mihajla Ostrograds'kogo, 4 (123). 78-83. DOI: 10.30929/1995-0519.2020.4.78-83 [In Ukrainian]. 